\title{
Tunable photoresponsive supramolecular systems
}

\author{
J-P. Desvergne, F. Fages, H. Bouas-Laurent and P. Marsau ${ }^{\circ}$ \\ Photophysique et Photochimie Moléculaire, CNRS URA 348 and 'Laboratoire de \\ Cristallographie et de Physique Cristalline, CNRS URA 144, Université de Bordeaux 1, \\ 33405 Talence Cedex, France
}

\begin{abstract}
Photoresponsive supramolecular systems based on the photochemical and photophysical properties of the anthracene ring have been designed and investigated in particular for their strong fluorescence dependence upon conformational effects, modulated by temperature, solvent polarity and complexation of charged species. Anthracenophanes (crown-ethers, cryptands) were shown to act as sensitive and specific probes for cation detection in diluted media and to be especially well suited for the study of oriented weak interactions between $\pi$ clouds and heavy cations $\left(\mathrm{Ag}(\mathrm{I}), \mathrm{TI}^{(\mathrm{I})} \ldots\right)$. In addition, a simple molecule, 2,3-didecyloxyanthracene, was found to be a gelating agent for alcohols, even at low concentration; the temperature dependent electronic absorption and fluorescence emission properties of the medium are suggestive of the microscopic organization of these new molecular assemblies.
\end{abstract}

\section{INTRODUCTION}

It was shown that photosensitive systems incorporating complexing units such as crown-ethers and cryptands enable the study of the interplay between photochemistry and cation complexation (ref. 1,2). These photochemical receptors can find applications in different areas as light modulated cation carriers or ions fluorescent probes (ref.3). In this contribution, we report selected examples developed in our group on supramolecular photoresponsive systems whose properties can be tuned by various factors such as electronic perturbation or addition of charged species, concentration changes, solvent polarity, temperature ... . The peculiar properties of these systems rest on the local arrangement of the subunit blocks, properties which conversely give first-hand information on the microscopic organization of the assembly.

The anthracene nucleus was selected as chromophore subunit because it displays an intense fluorescence emission in the visible range. This often dual emission constituted of a 'monomer' and an excimer contributions is sensitive to structural factors and the presence of other chemical species (ref. 4). Moreover as anthracenes smoothly photodimerize resulting in a considerable shift of their electronic absorption spectra (ref. 4), they could be used for inducing reversible conformational and optical changes in a supramolecular assembly.

The first and main part of the paper is devoted to cation complexing anthracenophanes acting as fluorescent probes for cation detections, some of them being perfectly suited for the study of oriented ion $\pi$ - cloud interactions.

The second part of this account deals with a different kind of supramolecular chemistry, concerning not two entities $A$ and $B$ forming a complex in an isotropic solution, but a simple molecule $M$ generating a gel with all the molecules of the "solvent". The connecting lead is the fluorescence of the gelating agent, 2,3didecyloxyanthracene. The temperature dependent spectroscopic properties of these assemblies are shown to enable a description of their microscopic organization.

\section{ANTHRACENOPHANES}

Our initial goal was to design systems whose photochemistry is cation-controlled. The open bisanthracenes 1 (and analogues) in which the two aromatic rings are linked by a complexing polyoxyethylene chain do not meet the requirements owing to the poor complexing ability of the linear $\left(\mathrm{CH}_{2} \mathrm{CH}_{2} \mathrm{O}\right)_{n}$ sequence (ref. 5); the cations 

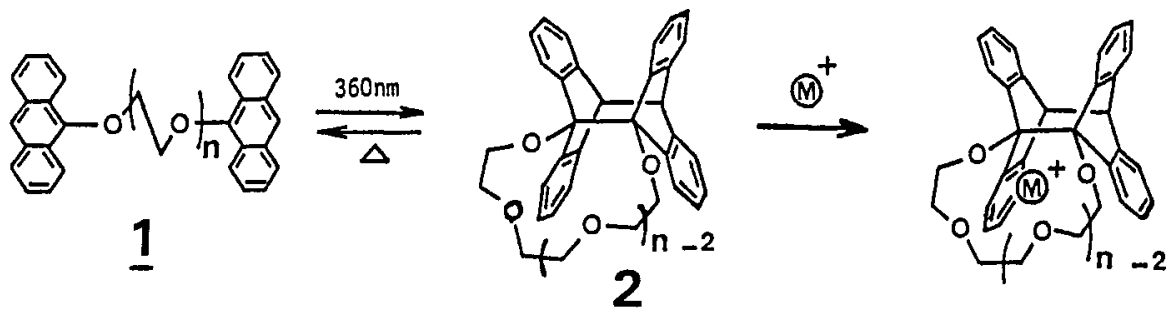

have only the effect of locking the thermally unstable photocyclomers $\underline{2}$ (dubbed "photocrowns"). A large increase in cation binding was however achieved under light irradiation with a guest selectivity governed by the number of oxygen atoms in the chain. Consequently, in order to enhance the complexing property of the systems several anthracenophanes displaying preformed cation traps were synthesized.

\section{1 ANTHRACENOPHANES INCLUDING TWO AROMATIC NUCLEI}

\section{I.1.1 Coronands}

Cyclophane AA55 (3), a large crown-ether derivative, in which A denotes one anthracene ring (anthracene-9,10diyl) and 5 the number of oxygen atoms between the chromophores was indeed found to fulfil the requirements (ref. 6); its photochemical properties are directed by the addition of sodium cations.
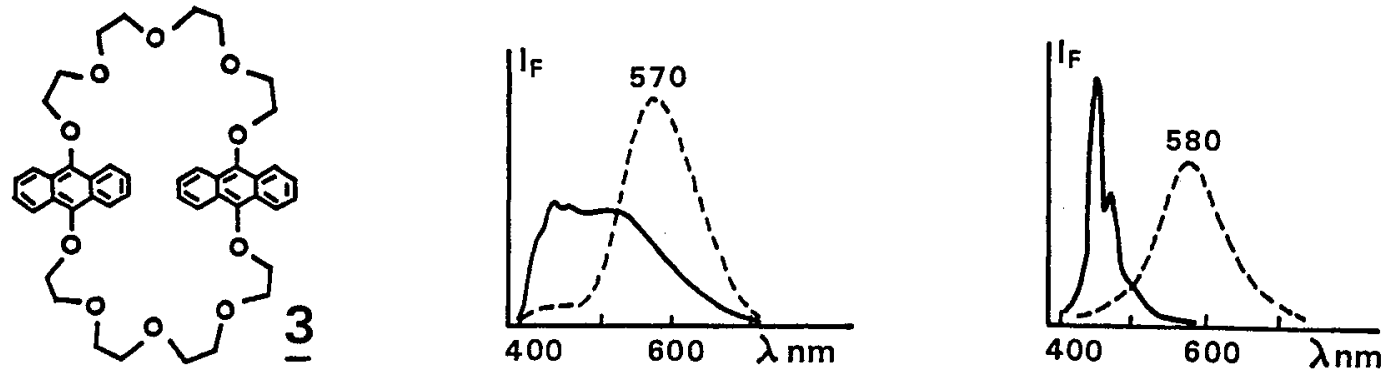

Fig. 1 Corrected fluorescence emission spectra at $20^{\circ} \mathrm{C}$ of AA55 (3).

Left: in methanol. Free ligand (-), in the presence of a large excess of $\mathrm{NaClO}_{4}(-)$.

Right : in the crystalline state. Free ligand $(-)$, disalt $2 \mathrm{Na}^{+}, \underline{\mathbf{3}}(-)$.

The free host exhibits, in methanol, a dual fluorescence emission spectrum with a structured part attributed to locally excited (monomer) species and a red-shifted, broad, structureless band ascribable to an excimer type emission (Fig.1).

The maximum intensity for excimer fluorescence points at $510 \mathrm{~nm}$, suggesting from previous work (ref. 7) the occurrence of partially overlapping excimers . Addition of sodium perchlorate induces a diminution of the monomer type band and an increase in intensity of the excimer contribution which is progressively shifted to the red to a final maximum at $570 \mathrm{~nm}$ for large amounts of salt. This value is consistent with the formation of a quasi-sandwich excimer. Single crystals of the sodium complex display pure excimer fluorescence with a
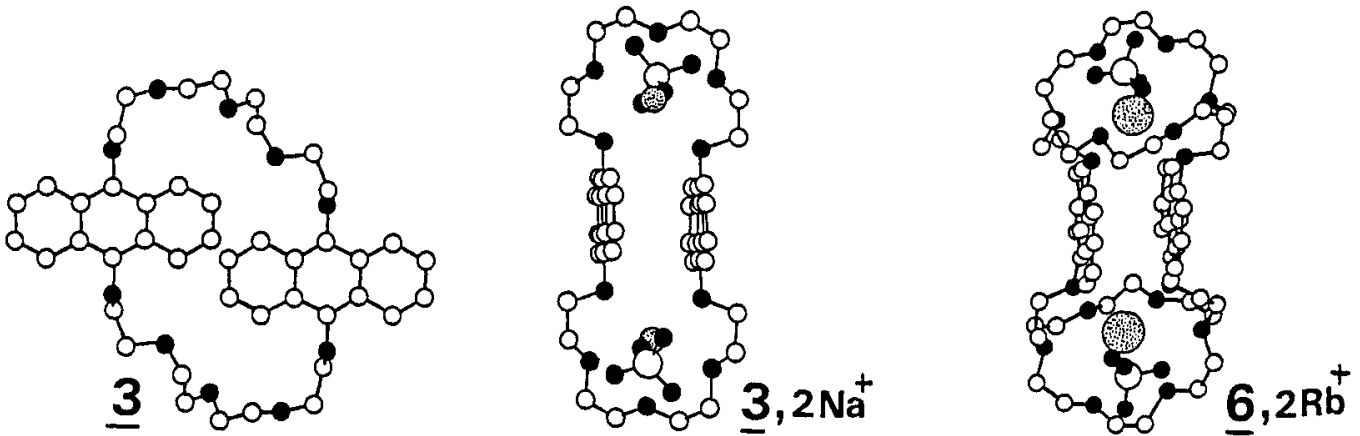

Fig. 2 X-ray crystal and molecular structure of $\underline{3}$, the disodium salt of $\mathbf{3}$ and the dirubidium salt of 6 . In the salts, the two anthracene rings are superimposed upon each other (van der Waals distance), but slightly staggered (ref. 12a). 
maximum emission $(\lambda=580 \mathrm{~nm}$ ) similar to that recorded with the fluid solution (Fig. 1), which points to identical conformations for the complexes. The $\mathrm{X}$-rays structure analysis (Fig. 2) reveals the quasi-sandwich geometry of the two aromatic rings . Single crystals of the free ligand present only a monomeric spectrum (Fig. 1) in accordance with the large distance and the absence of significant interactions between the anthracenes (ref. 8).

These observations also apply to crown benzenophane $\mathrm{CB}$ where $\mathrm{Na}^{+}$cation has been shown to modulate the fluorescence properties by inducing a strong conformational change (ref. 9).

The photoreactivity of AA55 is also cation-assisted; the free host $\mathbf{3}$ undergoes the dissymmetrical photocyclomer 4 through the 9,10 and $1^{\prime}, 4^{\prime}$ positions with a low quantum yield $\left(\Phi_{R} \approx 4 \times 10^{-4}\right)$ whereas the disalt leads only to the classical $9,10-9^{\prime}, 10^{\prime}$ photoproduct 5 with a higher efficiency $\left(\Phi_{R}>4 \times 10^{-3}\right)$.
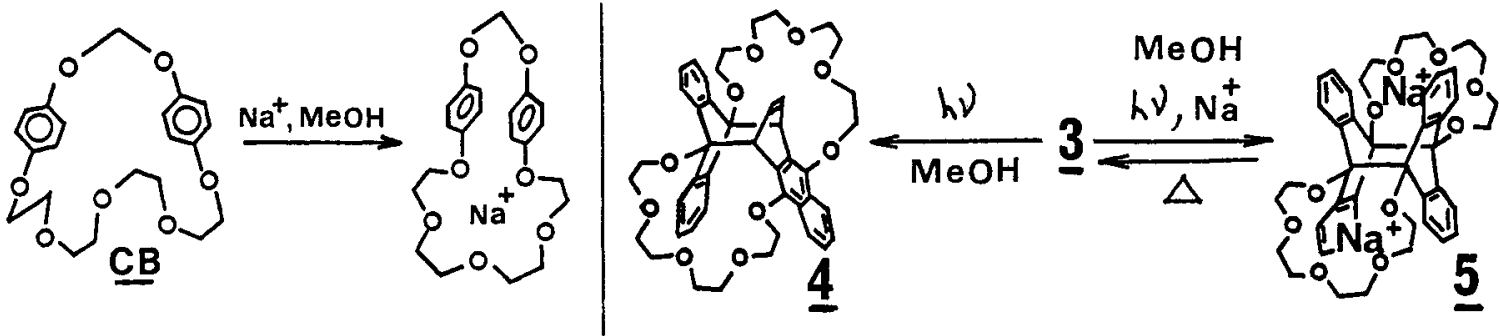

Besides, AA55 was shown (ref. 10) to form a 1:1 sandwich-type adduct with the flat-shaped $\mathrm{Pt}(\mathrm{bpy})\left(\mathrm{NH}_{3}\right)^{2+}$ (bpy $=2,2^{\prime}$-bipyridine) complex ion involving hydrogen bonds between ammonia ligand and the ethereal oxygens and a $\pi-\pi$ interaction between the bpy ligand and the anthracene moieties. The insertion of the $\mathrm{Pt}$ complex between the two aromatic halves accounts for the mutual inhibition of the photoreactivity and luminescence of both host and guest, at room temperature.

\section{$3+\mathrm{Pt}($ bpy $)\left(\mathrm{NH}_{3}\right)_{2} \longrightarrow 1: 1$ Sandwich inclusion complex}

Other anthraceno crown-ethers incorporating lactone functions were found to display a poor complexing ability presumably because of conformational strains of the molecular framework which prevents a stable coordination of the cation (ref. 11).

\section{I.1.2 Cryptands}

In order to strongly increase the complexing ability of the anthracenophanes, the macrotricyclic bisanthracene 6 dubbed "tonnelet" (small barrel), because of its shape was synthesized (ref. 12a). This fluorescent ditopic receptor is constituted of two hydrophilic diazacrown subunits and two anthracenes which delineate a large hydrophobic cavity.

The fluorescence emission of $\mathbf{6}$, in methanol, similar to that of $\mathbf{3}$ is dual (with a locally excited emission and excited complex band peaking at $\approx 450 \mathrm{~nm}$ and $530 \mathrm{~nm}$, respectively) but relatively weak in intensity $\left(\Phi_{\mathrm{F}}(\emptyset)=\right.$ $0.08, \Phi_{F}(3)=0.13$ ); the low intensity emission is attributed to the existence of several possible exciplexes between the amine groups and the aromatic rings, which are prone to collapse to non fluorescing ion-pairs in a polar solvent such as methanol (Fig.3). Addition of rubidium perchlorate induces in the spectrum the apparition of a new and strong red-shifted band $\left(\Phi_{\mathrm{FE}}=0.22\right)$ peaking at $560 \mathrm{~nm}$ at the expense of the monomer type fluorescence part $\left(\Phi_{F M}=0.02\right.$ ) (Fig. 3). These large spectral changes are specific to $\mathrm{Rb}^{+}$. The stability constants for the complexation of the first $\left(\mathrm{K}_{1}\right)$ and second $\left(\mathrm{K}_{2}\right)$ rubidium cations were determined by UV absorption spectroscopy (log $K_{1}: 5.8 ; \log K_{2}: 4.8$ ); no cooperative effect was observed (ref. 12b).
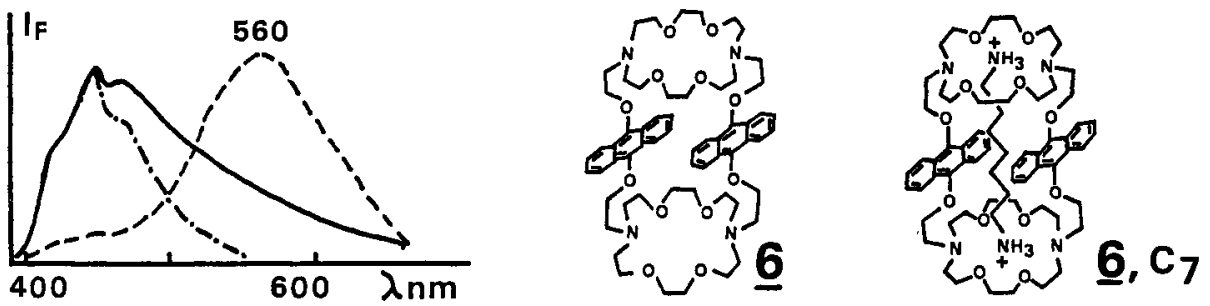

Fir. 3 Left: Corrected fluorescence emission spectra in degassed methanol of 6 , at $20^{\circ} \mathrm{C}$, conc $\approx 10^{-5} \mathrm{M}, \lambda_{\text {exc }} .380 \mathrm{~nm}$. Free ligand $(-)$, in the presence of a large excess of $\mathrm{RbClO}_{4}(-)$ and of $\mathrm{H}_{3} \mathrm{~N}^{+}-\left(\mathrm{CH}_{2}\right)=\mathrm{NH}_{3}{ }^{+}(\mathbf{C} 7)(--)_{-}$. Right : Hypothetical structure, based on UV, fluorescence and NMR studies of the inclusion complex between 6 and 1,7diaminoheptane dihydrochloride. 
As already demonstrated for AA55/2Na ${ }^{+}$, the fluorescence emission with $\mathrm{Rb}^{+}$is characteristic of a quasisandwich excimer whose formation results from the complexation of two $\mathrm{Rb}^{+}$which forces the two aromatic planes to adopt a superimposed configuration (Fig. 2).

Owing to previous observation with similar macrotricyclic molecules (ref.13) it was anticipated that the peculiar geometry of the ditopic receptor 6 could allow the recognition of dicationic molecular species by forming inclusion complexes provided that the entities present good structural fits.

If addition, in methanol, of cadeverine dication $\mathrm{H}_{3} \mathrm{~N}^{+}-\left(\mathrm{CH}_{2}\right)_{5}{ }^{+} \mathrm{NH}_{3}\left(\mathrm{C}_{5}\right)$ does not significantly alter the fluorescence of 6 , other linear $\alpha, \omega$-diammonium molecular salts $\left(C_{n}\right.$ with $\left.n \geq 6\right)$ having longer alkane chains produce large enhancements of the monomer-like emission with complete disappearance of the excimer type part (Table 1). The spectrum is similar to that displayed by 9,10-dimethoxyanthracene (DMO). The amplitude of the effect, dependent on the chain length, is maximum for $\mathrm{C}_{6}$ and $\mathrm{C}_{7}$ and slightly decreases while $\mathrm{n}$ increases. These results, supported by NMR and UV experiments, are consistent with the formation of dihaptocryptates in which the aromatic rings are prevented from forming an intramolecular excimer by the alkane chains (Fig. 3). That the fluorescence efficiency and the stability constants decrease for longer chains $C_{n}>C_{7}$ (see Table 1) suggest, in these cases, the occurrence of conformers where the two anthracenes are not completely separated from each other; the resulting interactions could quench the monomeric fluorescence without being conducive to fluorescent excimers. No strong modifications are recorded with $\mathrm{C}_{5}$ because it does not form an inclusion complex due to the too short $\left(\mathrm{CH}_{2}\right)_{5}$ chain; therefore, 6 could be used as a fluorescent sensor for the selective optical detection of rubidium cations and linear $\alpha, \omega$-diammonium molecular salts.

Anthracenophane $\mathbf{7}$ (ref.14) was synthesized with the purpose to enlarge the scope of anthracenes diazacrownethers for optical detection of other cations.

The fluorescence properties of $Z$ are mainly controlled by the degree of mutual overlap between the two aromatic nuclei which is sensitive to conformational changes of the complexing unit and the strain energy of the ethano bridge. In degassed methanol $\underline{7}$ is fairly fluorescent $\left(\Phi_{F}=0.30\right)$ and exhibits an excimer-like spectrum $\left(\lambda_{\max }\right.$ $515 \mathrm{~nm}$, Fig. 4). This emission is weakly perturbed by $\mathrm{Rb}^{+}\left(\lambda_{\max } 525 \mathrm{~nm}\right)$ and $\mathrm{Ag}^{+}\left(\lambda_{\max } 515 \mathrm{~nm}\right)$, the latter inducing a quenching of the fluorescence $\left(\Phi_{\mathrm{F}} \mathrm{Ag}+/ \Phi_{\mathrm{F}}=0.63\right)$ that presumably by increasing the nonradiative intersystem crossing efficiency. Interestingly, other heavy elements such as $\mathrm{Tl}^{+}$and $\mathrm{Th}^{4+}$ behave differently; the emission is distinctly blue-shifted $\left(\lambda_{\max } \approx 450-460 \mathrm{~nm}\right.$ ) and the actinide ion causes a net fluorescent enhancement $\left(\Phi_{\mathrm{F}} \mathrm{Th}^{4+} / \Phi_{\mathrm{F}}=1.63\right)$. It is assumed that the complexation of $\mathrm{Th}^{4+}$ and $\mathrm{Tl}^{+}$, in contrast to the other metal cations, requires a conformational reorganization of $\underline{Z}$ accompanied by a decrease of overlap between the anthracene moieties. One should note a marked difference with the bisanthryl crownether $\underline{8}$ known to exhibit a poor complexing ability towards metal cations (ref.4a).

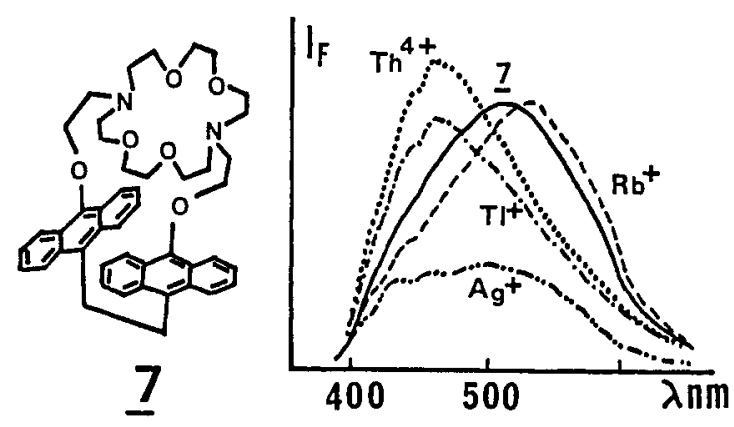

Fig.4 Corrected fluorescence emission spectra in degassed methanol at $20^{\circ} \mathrm{C}$, conc $10^{-5} \mathrm{M}, \lambda$ exc. $380 \mathrm{~nm}$, of the free ligand $\mathbf{Z}$ and in the presence of a large excess of different cation salts.
Table 1 Fluorescence emission quantum yields and stability constants (methanol/ chloroform) of inclusion complexes between $\mathrm{H}_{3} \mathrm{~N}^{+}-\left(\mathrm{CH}_{2}\right)_{\mathrm{n}^{-}}{ }^{+} \mathrm{NH}_{3}(\mathrm{Cn})$ and 6 at $20^{\circ} \mathrm{C}$. The stability constants were determined by UV absorption spectroscopy (ref. 12b).

\begin{tabular}{|lll|}
\hline $\mathbf{n}$ & $\Phi_{\mathrm{F}}$ & $\log \mathrm{K}$ \\
\hline 5 & 0.11 (dual emission) & $*$ \\
6 & 0.61 & 6.78 \\
7 & 0.55 & 7.16 \\
8 & 0.42 & 6.04 \\
9 & 0.51 & 6.26 \\
10 & 0.51 & 5.20 \\
12 & 0.21 & 4.60 \\
\hline
\end{tabular}

* No inclusion complexes 
In that connection, the weak fluorescence emission of the new four ring $\pi$-electron rich host 9 (the spectrum resembles that of 9,10 -dimethoxyanthracene, DMO) is totally quenched by $\mathrm{Th}^{4+}$ but moderatly deactivated by $\mathrm{Ag}^{+}$and $\mathrm{Tl}^{+}$. From structural factors and electronic considerations it is suggested in agreement with $\mathrm{UV}$ absorption spectroscopy that $\mathrm{Th}^{4+}$ (ionic radius: $0.95 \AA$ ) forms an inclusion complex with 2 whereas $\mathrm{Ag}^{+}(1.19$ $\AA)$ and $\mathrm{Tl}^{+}(1.49 \AA)$ seem to be coordinated with the aromatic rings outside the receptor (ref.14).
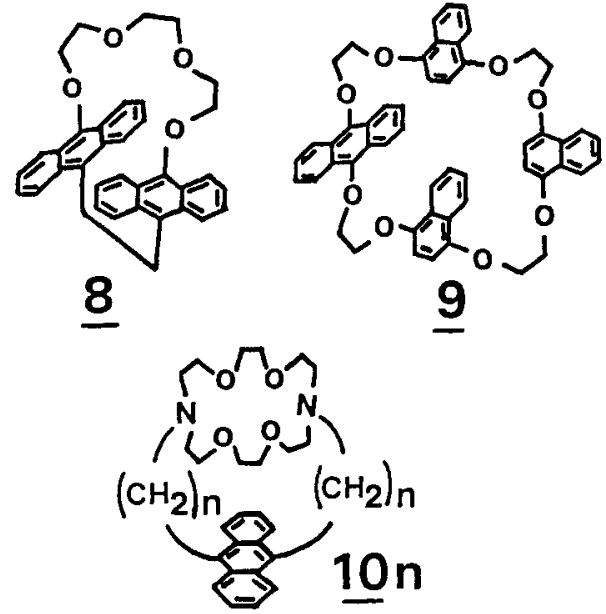
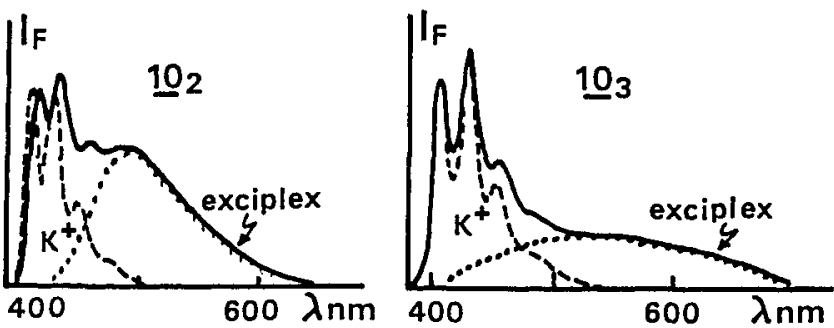

Fig. 5 Corrected fluorescence emission spectra at $20^{\circ} \mathrm{C}$ of $\underline{10}_{\mathrm{n}}$. Left: In $\mathrm{CH}_{2} \mathrm{Cl}_{2}$. Pure $\underline{10}_{2}(-)$, in the presence of $\mathrm{K}^{+}(\rightarrow$ (pure $\underline{10}_{2}$ displays the latter spectrum (---) in methanol). Right: In methanol. Pure $\underline{10}_{3}(-)$, in the presence of $\mathrm{K}^{+}(-)$ (*.os) represents the exciplex contribution.

\section{I.2 ANTHRACENOPHANES INCLUDING ONE AROMATIC NUCLEUS}

The photophysics of anthracenocryptands $\underline{10}_{n}(n=2,3)$ were directed by the intramolecular interactions, dependent on $n$, occurring between the aromatic ring and the nitrogen lone pairs of the complexing subunit (ref.15).

In solvents of low polarity (THF, $\mathrm{CH}_{2} \mathrm{Cl}_{2}$ and toluene) the fluorescence emission spectra of $\underline{10}_{\mathrm{n}}\left(\Phi_{\mathrm{FT}}=0.29\right.$ and 0.13 for $\mathrm{n}=2$ and 3 , respectively) exhibit a strong exciplex type emission ( $\Phi_{\mathrm{FE}}=0.23$ and 0.11 ) involving the nitrogens and the anthracene ring. Interestingly, compound $\underline{10}_{2}$ gives rise to a non linear triple exciplex where the two nitrogen lone pairs are symmetrically involved in an interaction with anthracene (ref. 16).

In methanol, the fluorescence emission efficiency of $\underline{10}_{3}$ dramatically decreases $\left(\Phi_{F}=0.04\right)$ due to the formation, via exciplex intermediates, of non fluorescent radical ions. Under the same conditions, $\underline{10}_{2}$ displays a strong fluorescence $\left(\Phi_{\mathrm{F}}=0.68\right)$ without any detectable exciplex contribution. $\underline{10}_{2}$ was assumed to develop Hbonds with the methanol molecules with the nitrogen lone pairs oriented outside the cavity, thus preventing exciplex formation. Addition of alkali or alkaline earth cations to methanolic solutions of the free hosts $\underline{10}_{n}$ induces a large fluorescence increase with the total disappearance of the exciplex emission for $\mathrm{10}_{3}$ (Fig. 5). This is consistent with the formation of $1 / 1$ inclusion complexes and the fact that the nitrogens participate in the complexation of the guest which relieves the intramolecular trichromophoric interactions. No effect was recorded with $\mathrm{Li}^{+}$because of its small dimension (ionic radius: $0.78 \AA$ ).

$\mathrm{Tl}^{+}$and $\mathrm{Ag}^{+}$, despite their coordination to the two nitrogen atoms, behave in a different way : they act as fluorescent quenchers (Table 2), especially with $\underline{10}_{2}$ (in which the average distance between the cation and the anthracene is shorter) and the complexes present special spectroscopic features (Fig. 6).

Table 2 Fluorescence quantum yields of $10 \mathrm{n}$ and 9,10-dipropylanthracene $(\mathrm{R})$ in methanol (conc. $\approx 10^{-5} \mathrm{M}, 20^{\circ} \mathrm{C}, \lambda_{\text {exc. }}$. $380 \mathrm{~nm}$ ) in the presence and absence of salts (ref. 15).

\begin{tabular}{|llllllll|}
\hline & Free ligand & $\mathrm{Li}^{+}$ & $\mathrm{Na}^{+}$ & $\mathrm{K}^{+}$ & $\mathrm{Ag}^{+}(\log \mathrm{K})$ & $\mathrm{T1}^{+}(\log \mathrm{K})$ \\
\hline$\underline{10}_{2}$ & 0.68 & 0.70 & 0.57 & 0.64 & $0.05(9.51)$ & 0.05 & $(8.52)$ \\
$\underline{10}_{3}$ & $0.04^{\#}$ & $0.05^{\#}$ & 0.17 & 0.30 & $0.23^{\#}(9.36)$ & 0.07 & $(7.07)$ \\
$\mathrm{R}$ & 0.76 & & & & 0.39 & 0.67 & \\
\hline
\end{tabular}

\# dual emission, $\log \mathrm{K}$ refers to the stability constant of the complex. 

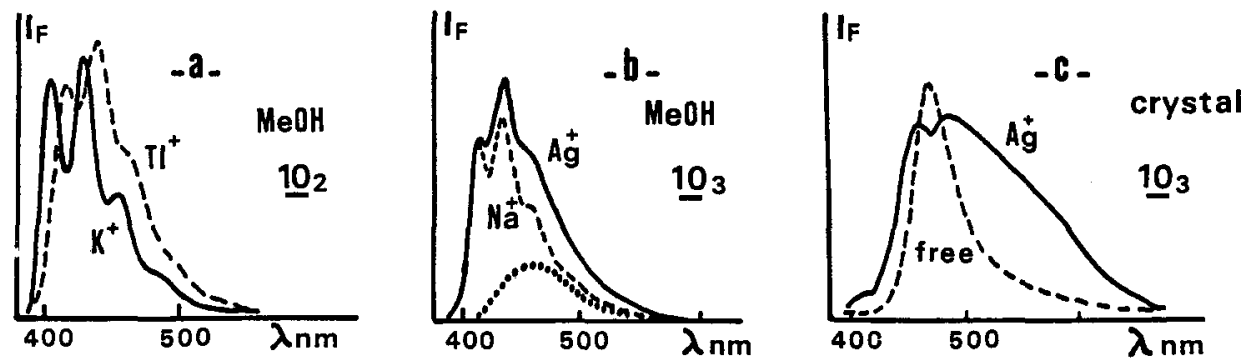

Fig.6 Corrected fluorescence emission spectra of $10_{n}$ $a:\left(\longrightarrow \frac{10}{2}\right.$ and $\mathrm{K}^{+},(-) 10_{2}$ and $\mathrm{Tl}^{+}$, in methanol.

b : (-) $1_{3}$ and $\mathrm{Ag}^{+},(--) 1_{3}$ and $\mathrm{Na}^{+}$, in methanol, (-m) represents the exciplex contribution.

c : (-) $\underline{10}_{3}$ and $\mathrm{Ag}^{+},(--)$pure $\underline{10}_{3}$, in the crystal.

The emission displayed by $\mathrm{Tl}^{+}$and $\underline{10} 2$ originates from an excited $\mathrm{Tl}^{+} /$anthracene complex formed in the ground state. The latter is revealed by UV spectroscopy and shows in its NMR spectrum coupling constants (120-140 Hz) between $\mathrm{Tl}^{+}$and aromatic carbons underlining the cation-anthracene interaction. With $10_{3}$, the fluorescence emission is close to that registered with light cations probably due to the larger size of the cavity, in agreement with NMR and UV spectroscopy.

The absorption spectra of $\underline{10}$ are affected by addition of $\mathrm{Ag}^{+}$which produces hypochromic and bathochromic shifts. The effect larger with $\underline{10}_{2}$ (10 and $4 \mathrm{~nm}$ for $\mathrm{n}=2$ and 3 , respectively) points to a ground-state complex between the ions and the aromatic ring. The analysis of the fluorescence emission of $\mathrm{10}_{2}$ in the presence of $\mathrm{Ag}^{+}$ shows that the corresponding ground state charge transfer complex $\left(\mathrm{Ag}^{+} /\right.$anthracene) is not light emitting whereas $\mathbf{1 0}_{3}$ solution displays a dual fluorescence with an exciplex (between $\mathrm{Ag}^{+}$and anthracene) peaking at $460 \mathrm{~nm}$.

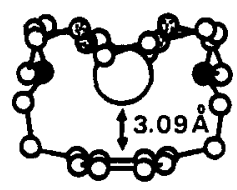

102. $A_{g}^{+}$

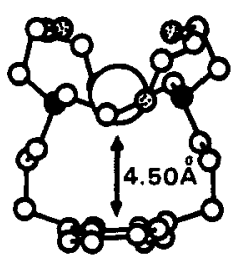

$10_{3} \cdot A_{g}^{+}$

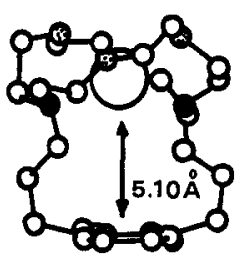

$10_{3} \cdot A_{g}^{+}$
Fig.7 Molecular structure, from $\mathrm{X}$-ray analysis (ref. 17), of $\mathrm{Ag}^{+}$complexes with $10_{\mathrm{n}}$. View of the molecules along the long axis of the anthracene ring.

In the crystal, the $102 / \mathrm{Ag}^{+}$complex is not fluorescent in contrast to $\underline{10}_{3} / \mathrm{Ag}^{+}$which exhibits a dual emission constituted of monomer and exciplex-like contributions (Fig. 6). Both the free hosts are fluorescent in the solid state, they present non structured spectra with a maximum intensity at $520 \mathrm{~nm}$ and $465 \mathrm{~nm}$ for $\mathrm{n}=2$ and $\mathrm{n}=3$, respectively (ref.17). X-ray crystallography of the complexes clearly shows that $\underline{10}_{n}$ encapsulates $\mathrm{Ag}^{+}$(Fig. 7). In the non-emitting complex $(\mathrm{n}=2)$ the distance between $\mathrm{Ag}^{+}$and anthracene is ca. $3.1 \dot{A}$. Two distinct coordination sites occur with $n=3$ involving larger $\mathrm{Ag}^{+}$-anthracene distances (4.5 and $5.1 \AA$ ). The monomeric emission was postulated to originate from the $5.1 \AA$ site whereas the other site is conducive to the exciplex. These results provide nice examples of a correspondence between clearly established molecular structures and fluorescence properties of the pair $\mathrm{Ag}^{+}$-anthracene.

\section{2,3-DIDECYLOXYANTHRACENE: A NOVEL LUMINESCENT GELLING AGENT}

A gel can be considered as a special case of supramolecular system where the solvent molecules are encircled in a network most often made of macromolecules. However some rare cases of small molecular gelling agents are known, one of which, 2,3-didecyloxyanthracene (11) was discovered in these laboratories (ref.18), the other noticeable examples are fluorinated alkanes which, in large concentrations, form gels with hydrocarbons and some recently found cholesterol derivatives capable to gel a variety of solvents (ref. 19). 

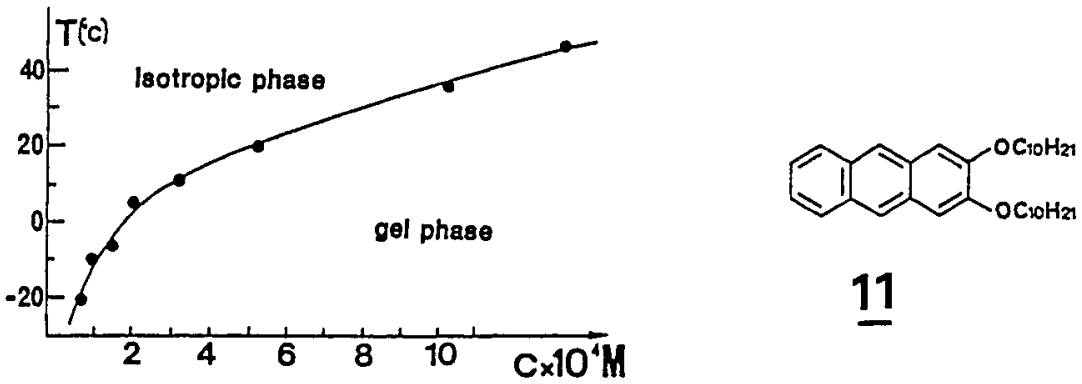

11

Fig. 8 Gelation temperature of methanolic solutions of $\underline{11}$ as a function of gelator concentration.

Compound 11 was shown to form thermoreversible translucent gels with alcohols at low concentrations $\left(\approx 10^{-4}\right.$ $\mathrm{M})$ and to a lesser extent with aliphatic amines and some hydrocarbons. Thus at room temperature one molecule of 11 can imprison up to 25,000 molecules of methanol, the most suitable solvent for gelation. The sol-gel process is temperature and concentration dependent, since cooling the isotropic solution lowers the minimum concentration of 11 necessary to build up the gel network (Fig. 8).

An electron micrograph of a gel obtained with $\underline{11}$ and alcohol shows a dense three-dimensional pattern composed of randomly oriented and intertwined fibrous bundles which delimit meshes encaging the isotropic fluid immobilized by surface tension. The fibers are constituted of several molecular threads joined together. Inspection of the gelling properties of structurally related molecules shows that the gelator framework has to display together the following characteristics : (1) three linearly fused rings (anthracene, anthraquinone ring, but not benzene, naphthalene, phenanthrene, stilbene ...), (2) two long alkoxy substituents located exclusively on 2 and 3 positions on the ring (the presence of only one long alkoxy group or two long aliphatic chains make the molecule inactive).
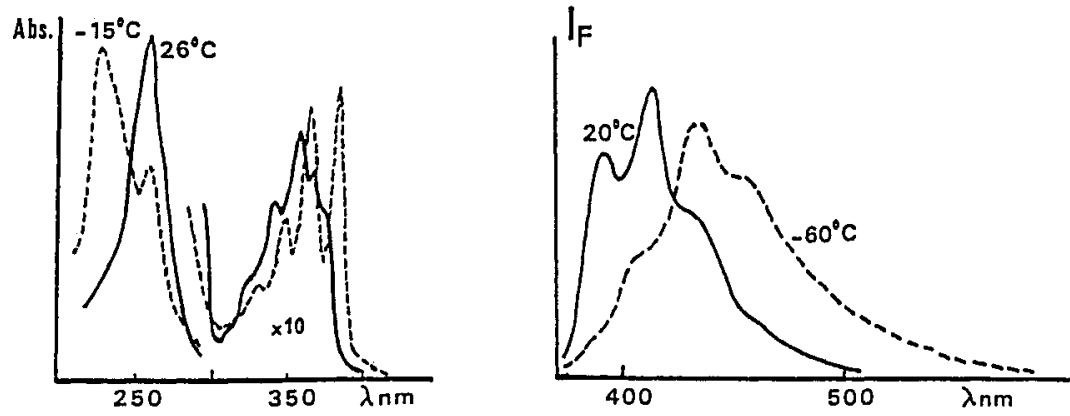

Fig.9 Left, isotropic (-) and gel (-) absorption spectra of 11 in methanol (conc $\approx 10^{-3} \mathrm{M}$ )

Right, isotropic $(-)$ and gel $(--)$ corrected fluorescence emission of $\underline{11}$ in methanol (conc $\approx 10^{-4} \mathrm{M}$ ).

Large spectral modifications of the anthracene chromophore are registered along the thermally controlled sol-gel transition (Fig. 9) so that the gelator acts as an internal sensor of the microscopic structural changes of the medium. The UV spectrum is smoothly transformed upon gelation with the apparition of several isosbestic points. Similarly, the fluorescence emission spectrum is red-shifted with large changes in shape when the isotropic solution progressively forms the gel. Analysis of fluorescence decays (nonexponential and wavelength dependent) and time-resolved spectroscopy indicate the occurrence of a variety of excited species resulting of different mutual orientations of the anthracene moieties with partially overlapped monomers.

From the spectroscopy study, it was proposed that the gelling agent forms assemblies where anthracene units exhibit anti-orientation (head-to-tail) with partial overlap between the aromatic nuclei. The solvents associated with 11 by H-bonds are believed to construct and strengthen the network which involves dipolar forces and van der Waals interactions. These new types of aromatic-based gelators might be applicable to the development of optical devices since the transmittance is reversibly changed by temperature or optical storage provided the aromatic displays reversible photoreactivity. 


\section{CONCLUDING REMARKS}

The common features of the systems examined in this account are based on the remarkable photophysical and photochemical properties of the anthracene ring which is connected in diverse ways to complexing units. Some particular results are emphasized :

- The interplay between structure and fluorescence emission was studied in fluid solutions and in parallel in the crystalline state. Owing to the fact that, in our case, the single crystals are made of clearly individualized molecules, their fluorescence reflects the molecular rather than the collective or defect properties and, thus, strongly suggests the conformational arrangements occurring in fluid solutions.

- Owing to their rigidity in addition to their complexing ability, anthraceno-cryptands have been shown to be unique in revealing weak host-guest oriented bonding such as anthracene- $\mathrm{Ag}^{+}$interactions, modulated as a function of their mutual distance.

- The macrotricyclic bisanthraceno ligand (so called "tonnelet") can be used as an optical sensor for the selective recognition of metal cations (in particular $\mathrm{Rb}^{+}$) and primary $\alpha, \omega$-diammonium aliphatic guests.

- Side ring substitution of anthracene by long aliphatic chains has allowed us to extend the field of fluorescing supramolecular systems to a new type of gels which apply to alcohols.

Future investigations are directed to further improve the selectivity, versatility and photoreversibility of these systems.

Acknowledgements Thanks are due to the CNRS for a special support of this work. We appreciate the contribution of all the colleagues and students whose names are cited in the references.

\section{REFERENCES}

1. a V. Balzani ed. Supramolecular Photochemistry, Reidel, Dordrecht (1987).

b J-M. Lehn in Frontiers in Supramolecular Organic Chemistry and Photochemistry, H.J. Schneider and

H. Dürr eds., VCH, Weinheim, (1991) p.1.

2. H. Bouas-Laurent, J-P. Desvergne, F. Fages and P. Marsau in Frontiers in Supramolecular Organic Chemistry and Photochemistry, H.J. Schneider and H. Dürr eds, VCH, Weinheim, (1991) p. 265.

3. O.S. Wolfbeis ed. in Fiber Optic Chemical Sensors and Biosensors, CRC Press, (1991) Vol.I and Vol.II.

4. a H. Bouas-Laurent, A. Castellan and J-P. Desvergne, Pure Appl. Chem. 2, 2633-2648 (1980).

$\mathrm{b}$ H. Bouas-Laurent and J-P. Desvergne in Photochromism; Molecules and Systems, H. Dürr and H.

Bouas-Laurent eds., Elsevier, (1990) p. 561-630.

5. J-P. Desvergne and H. Bouas-Laurent, Israel J. Chem., 18, 220-226 (1979).

6. H. Bouas-Laurent, A. Castellan, M. Daney, J-P. Desvergne, G. Guinand, P. Marsau and M-H. Riffaud, J. Am. Chem. Soc. 108, 315-317 (1986).

7. J. Ferguson, A. Castellan, J-P. Desvergne and H. Bouas-Laurent, Chem, Phys. Lett. 78, 446-450 (1981).,

8. P. Marsau, H. Bouas-Laurent, J-P. Desvergne, F. Fages, M. Lamotte and J. Hinschberger, Mol. Cryst. Liq. Cryst. Inc. Nonlin. Opt. 156, 383-392 (1988).

9. H. Hopf, R. Utermöhlen, C. Antonius, P. Marsau, J. Andrianatoandro, T. Willms, J-P. Desvergne and H. Bouas-Laurent, to be published.

10. L. Prodi, R. Ballardini, M.T. Gandolfi, V. Balzani, J-P. Desvergne and H. Bouas-Laurent, J. Phys. Chem. 25, 2080-2083 (1991).

11. J. Hinschberger, J-P. Desvergne, H. Bouas-Laurent and P. Marsau, J. Chem. Soc. Perkin II, 993-1000 (1990).

12. a F. Fages, J-P. Desvergne, H. Bouas-Laurent, J-M. Lehn, J.P. Konopelski, P. Marsau and Y. Barrans, L Chem. Soc. Chem. Comm., 655-658 (1990).

b F. Fages, A-M. Albrecht-Gary, J-M. Lehn et al., to be published.

13. A. Hamilton, J-M. Lehn and J.L. Sessler, J. Am. Chem. Soc. 108, 5158-5167 (1986) and references therein.

14. J-P. Desvergne, H. Bouas-Laurent, unpublished results.

15. F. Fages, J-P. Desvergne, H. Bouas-Laurent, P. Marsau, J-M. Lehn, F. Kotzyba-Hibert, A-M. AlbrechtGary and M. Al-Joubbeh, J. Am. Chem. Soc.111, 8672-8680 (1989).

16. F. Fages, J-P.Desvergne and H. Bouas-Laurent, J.Am. Chem. Soc. 111, 96-102 (1989).

17. J-P. Desvergne, F. Fages, H. Bouas-Laurent, J. Andrianatoandro and P. Marsau, to be published.

18. T. Brotin, R. Utermöhlen, F. Fages, H. Bouas-Laurent and J-P Desvergne, J. Chem. Soc. Chem. Comm. 416-418 (1991).

19. a Y.C. Lin, B. Kachar and R.G. Weiss, J. Am. Chem. Soc. 111, 5542-5551 (1989).

b K. Murata, M. Aoki, T. Nishi, A. Ikeda and S. Shinkai, J. Chem. Soc. Chem. Comm, 1715-1718 (1991).

c M. Aoki, K. Murata and S. Shinkai, Chem. Letters 1715-1718 (1991). 